\title{
Esophageal motility disorders: Current concepts of pathogenesis and treatment
}

Peter J Kahrilas MD

PJ Kahrilas. Esophageal motility disorders: Current concepts of pathogenesis and treatment. Can J Gastroenterol 2000;14(3): 221-231. Current concepts of esophageal motility disorders are summarized. Primary data sources were located via MEDLINE or cross-citation. No attempt was made to be comprehensive or inclusive of the literature because fewer than $10 \%$ of citations are discussed. Instead, emphasis was placed on new developments in diagnosis, therapeutics and practice patterns. Controlled therapeutic trials and pathophysiological observations are emphasized. Achalasia is a rare disease of failed lower sphincter relaxation and aperistalsis. Diffuse esophageal spasm (DES), an equally rare disease, is defined by nonpropagated esophageal contractions. Nonspecific motility disorders, including nutcracker esophagus and hypertensive lower esophageal sphincter, are identified only by manometry and are 10 times as prevalent. Neuromuscular pathology is evident only with achalasia (myenteric plexus neuron destruction). Pharmacological therapies have limited efficacy with achalasia, more limited efficacy with DES and no efficacy with the nonspecific motility disorders. More efficacious therapies for the nonspecific disorders are directed at associated reflux disease or psychiatric disorders. Pneumatic dilation is effective therapy for achalasia in $72 \%$ of instances but frequently requires repeat dilation and is complicated by a $3 \%$ perforation rate. Surgical myotomy is effective in $88 \%$ of patients with achalasia; morbidity from thoracotomy has been the major limitation but has been sharply reduced with a laparoscopic approach. In conclusion, although it has been suggested that esophageal motility disorders are distinct clinical entities, critical review of the literature supports this only in the case of achalasia, a disease of well defined pathophysiology, functional disturbance and therapies. This clarity diminishes progressively for DES and nonspecific esophageal motility disorders.

Key Words: Achalasia; Diffuse esophageal spasm; Esophageal motility disorders; Hypertensive lower esophageal sphincter; Nutcracker esophagus

\section{Troubles de la motilité œsophagienne : Notions actuelles de la pathogénie et du traitement}

RÉSUMÉ : Les notions actuelles sur les troubles de la motilité œsophagienne sont résumées. Les sources principales des données ont été obtenues par Medline ou par références croisées. On n'a pas cherché à faire une revue globale et inclusive de la littérature parce que les commentaires portent sur moins de $10 \%$ des articles. Au lieu de cela, on a mis l'accent sur les nouvelles avancées diagnostiques et thérapeutiques, et sur les nouveaux schémas de pratique, de même que sur les essais thérapeutiques comparatifs et les observations physiopathologiques. L'achalasie est une affection rare caractérisée par un manque de relâchement du sphincter œsophagien inférieur et par un apéristaltisme œsophagien. Le spasme diffus de l'œsophage (SDO), une affection également rare, se caractérise par des contractions œsophagiennes non propulsives. Les troubles non spécifiques de la motilité comprenant ceux de l'œsophage « casse-noisette » et l'hypertonicité du sphincter œsophagien inférieur, peuvent seulement être identifiés par manométrie et sont dix fois plus courants. Une pathologie neuromusculaire est évidente seulement dans le cas de l'achalasie (destruction des neurones du plexus myentérique). Les traitements pharmacologiques font preuve d'une efficacité limitée pour l'achalasie, encore plus limitée pour le SDO et nulle pour les troubles non spécifiques de la motilité. Des traitements plus efficaces pour les troubles non spécifiques visent le reflux œsophagien associé ou les affections psychiatriques. La dilatation pneumatique est un traitement efficace de l'achalasie dans $72 \%$ des cas, mais exige souvent des séances répétées et révèle un taux de perforation de $3 \%$. La myotomie par voie chirurgicale est efficace chez $88 \%$ des patients atteints d'achalasie ; la morbidité due à la thoracotomie demeurait un obstacle majeur, cependant, elle a été considérablement réduite par une approche laparoscopique. En conclusion, bien que l'on ait émis l'hypothèse que les troubles de la motilité œesophagienne soient des entités cliniques distinctes, une revue critique de la littérature n'étaye cette hypothèse que dans le cas de l'achalasie, une maladie dont la physiopathologie, les troubles fonctionnels et les traitements sont bien définis. Par contre, ces données deviennent de moins en moins claires dans les cas de SDO et des troubles non spécifiques de la motilité œsophagienne.

This mini-review was prepared from a presentation made at the American Congress of Gastroenterology, October, 1998, Boston, Massachusetts Department of Medicine, Northwestern University Medical School, Chicago, Illinois, USA

Correspondence and reprints: Northwestern University Medical School, Division of Gastroenterology and Hepatology, Department of Medicine,

Searle Building 10-541, 303 East Chicago Avenue, Chicago, Illinois 60611-3053, USA. Telephone 312-908-7925, fax 312-908-6192,

e-mailp-kahrilas@nwu.edu

Received for publication December 28, 1998. Accepted January 5, 1999 
$\mathrm{D}$ isordered esophageal motility was recognized long before there was adequate methodology to quantify it. Cardiospasm was described more than 300 years ago and characterized as a functional obstruction of the esophageal outlet with no obstructing lesion evident at autopsy. The initial concept of 'esophageal spasm' is attributable to Hamilton Osgood (1), based on his description of six patients with episodic chest pain and dysphagia in 1889: "sudden and often intense constriction in the epigastrium...with an arrest of food at the cardiac orifice". The modern concepts of these disorders came relatively recently, aided by advances in fluoroscopy and intraluminal manometry. Lendrum (2) proposed that the functional obstruction in cardiospasm was due to incomplete relaxation of the lower esophageal sphincter (LES) and renamed the disease achalasia ('failure to relax'). Introduction of the term 'diffuse esophageal spasm' (DES) followed Fleshler's (3) 1967 description of a

\section{clinical syndrome characterized by symptoms of substernal distress or dysphagia or both, the roentgenographic appearance of localized, non-progressive waves (tertiary contractions), and an increased incidence of nonperistaltic contractions recorded by intraluminal manometry}

During the past 20 years, with the continued evolution of manometric techniques (4) came the description of other aberrations of esophageal motility (nutcracker esophagus, hypertensive LES and nonspecific esophageal motor disorders). Unlike achalasia or esophageal spasm, identification of these conditions requires manometry because the esophagus is anatomically and radiographically normal. However, because these aberrations are readily identifiable manometrically, they are often conceptualized as motility disorders together with achalasia and DES. If that grouping is accepted, esophageal motility disorders clearly encompass a spectrum of aberration ranging from those of clear functional consequences to those of less clear implication. A similar spectrum of significance exists when one considers the therapeutic aspects of these disorders. With this in mind, the following review examines current concepts of the etiology and management of the spectrum of esophageal motility disorders (other than reflux disease).

\section{NORMAL ESOPHAGEAL MOTILITY}

The striated muscle (proximal) esophagus is controlled by excitatory vagal innervation, and peristalsis in this segment results from the sequential activation of motor units by the medullary swallowing centre in much the same way as the oropharyngeal musculature. Vagal control of the smooth muscle (distal) esophagus is more complex. Vagal fibres synapse on myenteric plexus neurons located between the longitudinal and circular muscle layers of the esophagus rather than directly at neuromuscular junctions. Although the relationship between morphology and function of the neurons remains undetermined, vagal stimulation can either excite or inhibit esophageal musculature depending on which myenteric plexus neurons are activated. Furthermore, the myenteric plexus neurons can independently organize peristalsis as evidenced by the integrity of secondary peristalsis after vagotomy. Excitatory neurons mediate contraction of both longitudinal and circular muscle layers via cholinergic receptors. Inhibitory neurons affect predominantly the circular muscle layer via nitric oxide nerves and exert a progressively prolonged inhibition at more distal esophageal loci (5). Cholinergic excitation of the excitatory myenteric plexus neurons is nicotinic, whereas that of the inhibitory neurons can be muscarinic as well. Both types of neurons innervate the entire smooth muscle esophagus including the LES. The process mediating LES relaxation is analogous to that mediating the inhibitory front along the esophagus except that it is more prolonged. The other unique feature of the sphincter is that it maintains a tonic contraction at rest by a myogenic mechanism (6).

Esophageal peristalsis begins as the pharyngeal contraction traverses the upper esophageal sphincter (UES), progressing at a speed of 2 to $4 \mathrm{~cm} / \mathrm{s}$. The longitudinal muscle of the esophagus also contracts sequentially during peristalsis with the effect of transiently shortening the esophagus by 2 to $2.5 \mathrm{~cm} \mathrm{(7).} \mathrm{Primary} \mathrm{peristalsis} \mathrm{is} \mathrm{that} \mathrm{initiated} \mathrm{by} \mathrm{a} \mathrm{swal-}$ low, whereas secondary peristalsis can be elicited in response to esophageal distension at any level. The propagation of the fluoroscopically imaged stripping wave corresponds with the manometric contraction such that the point of the inverted ' $\mathrm{V}$ ' at the bolus tail evident fluoroscopically occurs with the upstroke of the pressure wave (8). Immediately before luminal closure, an intrabolus pressure is recorded manometrically. The magnitude of the intrabolus pressure depends on the outflow resistance from the contracting segment; the greater the outflow resistance, the greater the recorded intrabolus pressure before luminal closure. The distinction between recordings of intrabolus pressure and contractile pressure within a sealed lumen can only be accurately made by using concurrent fluoroscopic imaging (9).

Recent analyses of the vigor and propagation of esophageal peristalsis have used a topographical representation to examine the synchrony and persistence of contraction among esophageal segments. The topographical analysis reveals not only a proximal transition zone between the striated and smooth muscle in the region of the aortic arch, but also a segmental characteristic of peristalsis through the smooth muscle esophagus with two distinct contractile segments followed by the LES (which contracts with vigor and persistence quite dissimilar to the adjacent esophagus) (10). Topographical analysis provides an explanation for double peaked contractile waves often seen in manometric recordings. A bipeaked contraction can occur in the zone of overlap between adjacent contractile segments if they are not precisely synchronized such that the distal segment contraction is delayed relative to the proximal zone.

Another property of normal esophageal motility is deglutitive inhibition. Swallowing inhibits all ongoing esophageal contraction. With a series of swallows at short intervals, the esophagus remains inhibited and quiescent with the LES relaxed. After the last swallow in the series, a normal peristaltic contraction occurs. Basal LES tone is inhibited with swal- 
TABLE 1

Perturbations of esophageal motility used to characterize proposed esophageal motility disorders

\begin{tabular}{|c|c|c|c|c|}
\hline & \multicolumn{2}{|c|}{ Disordered inhibition } & \multicolumn{2}{|c|}{ Disordered excitation } \\
\hline & Excessive & Inadequate & Excessive & Inadequate \\
\hline UES & - & $\begin{array}{l}\text { Cricopharyngeal bar* } \\
\text { Parkinson's disease } \\
\text { Belch dysfunction }\end{array}$ & - & - \\
\hline Body & - & $\begin{array}{c}\text { Achalasia } \\
\text { Pseudoachalasia* } \\
\text { Diffuse esophageal spasm }\end{array}$ & $\begin{array}{l}\text { Nutcracker esophagus } \\
\text { Diffuse esophageal spasm } \\
\text { Vigorous achalasia }\end{array}$ & $\begin{array}{c}\text { Advanced achalasia } \\
\text { Pseudoachalasia* } \\
\text { GERD } \\
\text { Scleroderma } \\
\text { Obstruction* } \\
\text { Nonspecific disorders }\end{array}$ \\
\hline LES & GERD & $\begin{array}{c}\text { Achalasia } \\
\text { Pseudoachalasia* }\end{array}$ & $\begin{array}{c}\text { Achalasia } \\
\text { Pseudoachalasia* } \\
\text { Hypertensive LES }\end{array}$ & $\begin{array}{c}\text { GERD } \\
\text { Scleroderma }\end{array}$ \\
\hline
\end{tabular}

*Conditions in which structural abnormalities mimic motility disorders. GERD Gastroesophageal reflux disease; LES Lower esophageal sphincter; UES Upper esophageal sphincter

TABLE 2

Prevalence of manometric abnormalities (mean among studies) in chest pain and dysphagia patients

\begin{tabular}{|c|c|c|c|c|c|}
\hline Inclusion criteria of study population & $\mathbf{n}$ & Achalasia (\%) & DES (\%) & Other* (\%) & Total abnormal (\%) \\
\hline Chest pain patients with negative cardiological evaluation & 1372 & 2.1 & 3.2 & 51.6 & 57 \\
\hline Patients with dysphagia as the principal symptom & 251 & 19 & 7 & 32.0 & 58 \\
\hline
\end{tabular}

*Includes nutcracker esophagus, hypertensive lower esophageal sphincter and nonspecific disorders. DES Diffuse esophageal spasm. Adapted with permission from reference 4

lowing concurrently with deglutitive inhibition. Deglutitive inhibition is also demonstrable in the tubular esophagus by creating an artificial high pressure zone by distending the esophageal lumen with a balloon and recording contractile pressure between the balloon and the esophageal wall. Once the high pressure zone is established in the normally flaccid tubular esophagus, deglutitive inhibition can be demonstrated throughout the length of the esophagus commencing concurrently with the pharyngeal swallow (11). The persistence of deglutitive inhibition at each esophageal locus determines the propagation velocity of esophageal peristalsis. Experimentally eliminating the effects of inhibitory nerves of the myenteric plexus with a nitric oxide scavenger (hemoglobin) results in a simultaneous esophageal contraction (12).

\section{ESOPHAGEAL MOTILITY DISORDERS}

As outlined above, the physiological components of esophageal motility involve the coordinated excitation and inhibition of the circular and longitudinal muscle layers of the esophagus. It follows that pathophysiological processes can be categorized as dysfunction of deglutitive inhibition (including sphincter relaxation) and/or of propagated excitation. Esophageal motility disorders are defined by manometric and in some cases fluoroscopic features suggestive of impaired function. In fact, because esophageal motor disor- ders are not diagnosed on histopathological grounds, their diagnosis depends on the definition of these functional aberrations. Even in the unusual circumstance of having an esophageal specimen to examine histopathologically, this can potentially be used to define an esophageal motility disorder only in the case of achalasia where there is gross esophageal dilation and a quantifiable decrement in the number of ganglion cells of the myenteric plexus. Table 1 is an attempt to categorize esophageal motility disorders on the basis of characteristics of inhibition and excitation. There are relatively few well defined motility disorders and, as one might predict, some overlap in functional characteristics (Table 1). However, such is the state of the art, and as will become evident, in some circumstances it can be very difficult to choose among the diagnostic possibilities.

The best defined esophageal motility disorder, achalasia, is rare, with an incidence estimated at one per 100,000 population (13-15). No population-based studies exist on the prevalence of other esophageal motility disorders. Thus, the best approximation of their incidence is obtained by examining data on populations at risk (patients with chest pain and/or dysphagia) and referencing the observed frequency of the other disorders to that of achalasia. As detailed in Table 2 (4), the prevalence of diffuse esophageal spasm is similar to that of achalasia, while the prevalence of other disorders (including nutcracker esophagus) is as much as 10 times greater. 
TABLE 3

Manometric criteria for esophageal motility disorders

\section{Defining criteria}

\section{Motility disorder}

Achalasia

Vigorous achalasia

Diffuse esophageal spasm

Nutcracker esophagus

Hypertensive LES

Nonspecific esophageal motor disorder
Required findings

Incomplete deglutitive LES relaxation

Absent peristalsis in the smooth muscle esophagus*

Incomplete deglutitive LES relaxation

Simultaneous deglutitive contractions in the smooth

muscle esophagus (greater than $40 \mathrm{mmHg}$ )

Simultaneous contractions in the smooth muscle esophagus with $30 \%$ or more of swallows

Mean distal esophageal peristaltic amplitude greater than $180 \mathrm{mmHg}$

Normal deglutitive LES relaxation

Increased resting LES pressure (greater than $40 \mathrm{mmHg}$ ) Normal deglutitive LES relaxation

Peristaltic abnormalities of insufficient severity to establish any of the above diagnoses, yet not felt to be normal
Associated findings

Elevated LES pressure

Elevated intraesophageal pressure

Repetitive contractions (more than two peaks)

Prolonged contractions (longer than $6 \mathrm{~s}$ )

High amplitude contractions (greater than $180 \mathrm{mmHg}$ )

Spontaneous contractions

Repetitive contractions (more than two peaks)

Prolonged contractions (longer than $6 \mathrm{~s}$ )

Increased resting LES pressure (greater than $40 \mathrm{mmHg}$ )

Frequent nontransmitted contractions (more than 20\% water swallows)

Retrograde contractions

Repetitive contractions (more than two peaks)

Low amplitude contractions (less than $30 \mathrm{mmHg}$ )

Prolonged contractions (more than $6 \mathrm{~s}$ )

High amplitude contractions (greater than 180 mmHg)

Spontaneous contractions

Incomplete LES relaxation

*The distal half of the esophagus is composed of smooth muscle while the proximal segment exhibits a gradual transition from striated to smooth muscle. LES Lower esophageal sphincter

Variability in the prevalence values of these disorders among studies is probably attributable to nonuniform definitions of the disorders as well as to the variable inclusion criteria of patient populations studied (4). Representative defining criteria for the family of esophageal motility disorders are shown in Table 3.

Dysphagia is the most fundamental symptom of an esophageal motility disorder. Esophageal as opposed to oropharyngeal dysphagia is suggested by the absence of associated aspiration, cough or oral residue. On the other hand, the associated conditions of heartburn, esophagopharyngeal regurgitation, chest pain, odynophagia or intermittent esophageal obstruction are suggestive of esophageal dysphagia. However, an important limitation of the patient history with esophageal dysphagia is that patient localization of obstruction is inaccurate. A distal esophageal obstruction caused by an esophageal ring or achalasia may be sensed as cervical dysphagia, making patients correct in localizing the dysfunction only $60 \%$ of the time. Thus, the entire esophagus should be considered in the evaluation of dysphagia regardless of where the patient localizes the problem. Another historical point suggestive of a motor disorder is difficulty with both solids and liquids as opposed to only solids, which is more suggestive of mechanical obstruction.

\section{UES}

Categories of UES dysfunction are included in Table 1 but not in Table 3 because although disorders have been described, the criteria for defining these are poorly defined.
Review of the literature on UES manometry reveals no clinical significance of measuring UES pressure and no validated criteria for defining impaired relaxation (4). Nonetheless, the term 'cricopharyngeal achalasia' is frequently encountered in the literature and requires explanation. In some contexts this term is used to imply failure of UES relaxation, in other instances it implies impaired UES opening, and in still others it is clear that the writer is not cognizant of the distinction. Given this vagary of meaning, I strongly suggest that the term be avoided altogether. Current understanding of UES function emphasizes that relaxation can occur without sphincter opening and vice versa. Inadequate opening principally occurs in the setting of neuromuscular dysfunction or a cricopharyngeal bar; inadequate relaxation can be seen in Parkinson's disease or with belch dysfunction. These disorders are briefly discussed below; a more comprehensive review of the topic can be found in a recent American Gastroenterology Association technical review (16).

A frequent finding during a barium swallow $\mathrm{x}$-ray is the appearance of a cricopharyngeal indentation (bar). Manometric studies have shown that cricopharyngeal bars are associated with increased hypopharyngeal intrabolus pressure during swallowing. Whereas normal individuals have upstream intrabolus pressure ranging from 6 to $18 \mathrm{mmHg}$ as the swallow volume is increased from 2 to $30 \mathrm{~mL}$, patients with cricopharyngeal bars have pressures ranging from 13 to $68 \mathrm{mmHg}$ for the same bolus volumes (17). Thus, although the cricopharyngeus relaxes normally during a swallow, it cannot distend normally. The same phenomena have been 
demonstrated in patients with Zenker's diverticula, suggesting that the diverticulum is an eventual consequence of the increased stress on the hypopharynx (18). Zenker's diverticula usually occur in men over 60 years of age, with the origin of the herniation in the midline between the oblique fibres of the inferior pharyngeal constrictor and the cricopharyngeus muscle (Killian's dehiscence). Specimens of cricopharyngeus muscle from patients with hypopharyngeal diverticula are consistent with the concept of a restrictive myopathy revealing muscle fibre degeneration with fibroadipose tissue replacement (19). The treatment of hypopharyngeal diverticula is cricopharyngeal myotomy with or without a diverticulectomy. Diverticulectomy alone risks recurrence because the underlying cricopharyngeal stenosis is not remedied; myotomy alone risks not solving the problem of food accumulation within the diverticula with attendant regurgitation and aspiration.

Recent studies have shown a 25\% prevalence of impaired UES relaxation in Parkinson's disease $(20,21)$. Despite the impaired relaxation, sphincter opening is normal, making this abnormality definable only with combined manometry and fluoroscopy. However, impaired UES relaxation is not correlated with either the severity of the associated pharyngeal motor disorder nor with the severity of dysphagia (20). Nonetheless, a favourable response to myotomy has been reported in one small series of four patients (many of whom had coexistent structural abnormalities). Clearly, more data are required before surgery can be recommended for this condition. Similarly, there has been little systematic evaluation of the responsiveness of dysphagia to anti-Parkinsonian medication. One study found that a combination of levodopa and swallow therapy improved swallow function, but it is uncertain to what extent improvement can be attributed to pharmacotherapy per se (22).

UES relaxation also occurs during belching in the following sequence:

1. Transient LES relaxation inhibiting the LES and the crural diaphragm.

2. Gastroesophageal gas reflux, distending the esophagus.

3. Complete relaxation of the UES, causing it to remain open longer than during swallowing, allowing the retrograde passage of air (23).

Additionally, reflexive glottal closure and limited anterior motion of the hyoid and thyroid cartilage occur, protecting the laryngeal inlet and opening the relaxed sphincter (24). This UES response can be reproduced by gaseous distention of the esophageal lumen; sudden gas distention triggers UES relaxation, which is more consistently present and persists for a longer period with larger volumes. Dysfunction of this reflex has been associated with painful esophageal distension in case reports (25).

As mentioned above, cricopharyngeal myotomy can be an effective mode of therapy for patients with hypopharyngeal diverticula, cricopharyngeal bars or Parkinson's in some instances. The criteria for performing a myotomy should be the presence of significant dysphagia leading to local discomfort, weight loss or aspiration; confirmation of UES dysfunction by videoradiography, preferably with intraluminal manometry; and absence of clinically significant gastroesophageal reflux or regurgitation (26). These criteria are often met in the case of hypopharyngeal diverticula, but probably not in many other instances. Although myotomy is a relatively safe procedure and can be performed with only local anesthesia, sudden death from aspiration is a reported complication, emphasizing the need to assess LES competence preoperatively. Esophageal dilation is also theoretically beneficial in the treatment of cricopharyngeal bars, and small clinical series have corroborated this. Data on the efficacy of dilation in this setting are, however, much more limited than in the case of myotomy (16).

\section{ACHALASIA}

The defining characteristics of achalasia are failure of the LES to relax completely with swallowing and aperistalsis in the smooth muscle esophagus. The resting LES pressure is elevated in approximately $60 \%$ of achalasia cases. If there are nonperistaltic, spasm-like contractions in the esophageal body, the disease is referred to as vigorous achalasia. Achalasia is thought to result from postganglionic denervation of the smooth muscle esophagus either as a result of Trypanasoma cruzi infection as in Chagas' disease or, more commonly, as an idiopathic entity. It is unclear whether the disease selectively affects excitatory or inhibitory neurons, but functionally, inhibitory neurons are necessarily impaired as an early manifestation of the disease. Sifrim et al (27) used an intraesophageal balloon to demonstrate impairment of deglutitive relaxation in the esophageal body as well as the LES in early, nondilated cases of achalasia. Previously referred to as nonadrenergic, noncholinergic neurons, it is now accepted that the neurons responsible for deglutitive inhibition (including sphincter relaxation) use nitric oxide as a neurotransmitter (28). In support of this conclusion, patients with achalasia have been shown to lack nitric oxide synthase in the gastroesophageal junction, and animal models of achalasia have been established using nitric oxide inhibitors.

Clinical manifestations of achalasia may include dysphagia, regurgitation, chest pain, weight loss and aspiration pneumonia. Regurgitation is particularly likely when large amounts of food are retained in the dilated esophagus. Classically, patients complain of regurgitant on their bed sheets when sleeping supine and often elect to sleep with several pillows or upright in a chair. Chest pain is a frequent complaint early in the course of the disease; its etiology is unclear. An interesting but fortunately rare symptom of achalasia is tracheal compression and airway compromise as a result of the dilated esophagus compressing the trachea.

The diagnosis of achalasia is made by barium swallow $\mathrm{x}$-ray or esophageal manometry. The characteristic $\mathrm{x}$-ray is of a dilated intrathoracic esophagus with an air-fluid level. The LES tapers to a point giving the distal esophagus a beak-like appearance. The beak does not open with swallowing but opens following the inhalation of amyl nitrite (a 
TABLE 4

Efficacy of medical and surgical treatment in achalasia

\begin{tabular}{|c|c|c|c|}
\hline \multirow[b]{2}{*}{ Therapy } & \multirow[b]{2}{*}{ Total $\mathbf{n}$} & \multicolumn{2}{|c|}{$\begin{array}{l}\text { Treatment efficacy without further } \\
\text { therapy }\end{array}$} \\
\hline & & $\begin{array}{c}\text { Response rate } \\
\text { (weighted mean } \\
\pm \text { SD among } \\
\text { studies, \%)* }\end{array}$ & $\begin{array}{c}\text { Duration of } \\
\text { follow-up } \\
\text { (weighted mean, } \\
\text { years)* }\end{array}$ \\
\hline Botulinum toxin & 149 & $32 \pm 19$ & 1.1 \\
\hline Pneumatic dilation & 1276 & $72 \pm 26$ & 4.9 \\
\hline \multicolumn{4}{|l|}{ Heller myotomy } \\
\hline Thoracotomy & 1221 & $84 \pm 20$ & 5 \\
\hline Laparotomy & 732 & $85 \pm 18$ & 7.6 \\
\hline Laparoscopy & 171 & $92 \pm 18$ & 1.2 \\
\hline
\end{tabular}

Pooled estimate of response rate of achalasia treatments. In calculating the weighted mean response for each treatment modality $(\hat{p})$, studies that were included were characterized by the number of subjects ( $n$ ) and the response rate for those subjects (p). Only studies including more than 10 patients and with a follow-up of one year or longer were tabulated.

$* \hat{p}=\frac{n_{1} p_{1}+n_{2} p_{2}+n_{x} p_{x}}{n_{1}+n_{2}+n_{x}} S E(\hat{p})=\sqrt{\frac{p_{1}\left(1-p_{1}\right)}{n_{1}}+\frac{p_{2}\left(1-p_{2}\right)}{n_{2}}+\frac{p_{x}\left(1-p_{x}\right)}{n_{3} n_{x} ? ?}}$

Adapted with permission from reference 38

smooth muscle relaxant). The defining manometric features are aperistalsis and incomplete LES relaxation. Other manometric features (hypertensive LES, increased intraesophageal baseline pressure or isobaric waveforms) provide supportive evidence of achalasia. A recent analysis found that manometrically defined impaired LES relaxation by itself (to a nadir pressure of more than $12 \mathrm{mmHg}$ ) had a $92 \%$ sensitivity and $94 \%$ specificity for the detection of achalasia (29). In a comparison of diagnostic modalities, a prospective study showed that achalasia was suggested by the radiologist in only 21 of 33 patients who were given this diagnosis at manometry; endoscopists prospectively suggested the correct diagnosis in less than one-third of the patients (14).

It is important to emphasize that neither the radiographic nor the manometric features of achalasia are specific for idiopathic achalasia or achalasia associated with Chagas' disease; tumour-related pseudoachalasia accounts for up to $5 \%$ of cases meeting the manometric criteria of achalasia. Pseudoachalasia is more likely with progressive age, abrupt onset of symptoms and early weight loss (30). Tumour infiltration (especially carcinoma in the gastric fundus) can completely mimic the functional impairment seen with idiopathic achalasia (see Table 1). It is because of this pitfall that a thorough anatomical examination including endoscopy should be done as part of the diagnostic evaluation of every new case of achalasia (31). A clue to the presence of pseudoachalasia on the endoscopic examination is of more than the slightest resistance of passage of the endoscope across the gastroesophageal junction; in idiopathic achalasia, the endoscope should pop through with only gentle pressure required. If suspicion of pseudoachalasia persists, endoscopic biopsy, computerized tomography, magnetic resonance imaging or endoscopic ultrasound should be considered for further evaluation depending on the special circumstances.

Another potential complication of achalasia is the development of esophageal carcinoma, the estimated risk of which ranges from zero- to 33 -fold. The only population-based study found a 16-fold risk among 1062 achalasia patients with 9864 years of follow-up (32). Therapy has not been shown to eliminate the cancer risk, evident by reported cases occurring years after either medical or surgical treatment. However, despite the 16-fold relative risk, the absolute risk of cancer remains slight, and an estimated 681 annual surveillance endoscopies would detect only one incident cancer among achalasia patients; surveillance is not advocated by national gastroenterology societies.

\section{MANAGEMENT}

No existing therapy for achalasia reverses the underlying neuropathology or restores normal deglutitive LES relaxation and peristalsis. Instead, therapies are aimed at reducing the LES pressure so that gravity can then facilitate esophageal emptying. Improved esophageal emptying should then reduce the symptoms and complications associated with esophageal retention. However, because no data exist on the prevention of complications, therapeutic efficacy can only be assessed by symptomatic or functional improvement. Functional improvement can be quantified manometrically (33), by barium swallow or by scintigraphy. However, in the absence of accepted criteria allowing comparison among therapeutic modalities, most series simply report a clinical assessment of efficacy, emphasizing the relief of dysphagia. Although the meaning of such descriptions varies, there is no alternative but to compare therapeutic modalities by this outcome measure.

As alluded to above, therapies for achalasia are primarily aimed at reducing LES pressure, be it phamacologically, by mechanical dilation or by surgery. Before botulinum toxin, the largest reported pharmacological experience was with isosorbide dinitrate or nifedipine, administered orally or sublingually before eating. Isosorbide dinitrate 5 to $10 \mathrm{mg}$ sublingually reduces the resting LES pressure by $66 \%$ for 90 mins. Calcium channel blockers (diltiazem, nifedipine, verapamil) reduce the LES pressure $30 \%$ to $40 \%$ for longer than $1 \mathrm{~h}(34,35)$. In practice, these drugs have marginal effectiveness and bothersome side effects. Thus, oral or sublingual pharmacological therapy is primarily useful in the early phases of achalasia for patients with mild or intermittent symptoms, or as a temporizing measure while more definitive treatments are contemplated.

A recently devised pharmacological therapy for achalasia is the endoscopic injection of $80 \mathrm{U}$ of botulinum toxin directly into the LES using a sclerotherapy catheter. Botulinum toxin inhibits acetylcholine release from nerve endings, reducing the LES pressure by $60 \%$ in pigs and $33 \%$ in humans (36). The site of action may be ganglionic or postganglionic. Its effect is eventually reversed by the formation of new synapses, making it somewhat predictable that, even 
if efficacious, it will not have lasting benefit (Table 4). In the longest reported follow-up, only one of 31 patients in a prospective trial of botulinum toxin had a response sustained for longer than two years (37). Thus, although botulinum toxin injection is an intriguing therapeutic approach for achalasia, its limitations are that it is less effective in reversing the functional consequences of achalasia than are other available therapies, it predictably needs to be repeated at roughly annual intervals, the consequences of repeated injections are unknown and it is relatively expensive (38). It appears, therefore, that outside of clinical trials, this therapeutic option should be reserved for elderly or frail individuals who are poor risks for more definitive treatments.

Therapeutic dilation for achalasia is accomplished with a balloon dilator designed to distend the LES to a diameter of 3 to $4 \mathrm{~cm}$ and reduce LES pressure by partially disrupting the sphincteric muscle. Only very temporary benefit is achieved when standard esophageal dilators are used. In instances of an unsatisfactory result, pneumatic dilation can be repeated once or twice. The major complication of pneumatic dilation is esophageal perforation. If perforation is suspected because of postprocedure pain or subcutaneous emphysema a gastrograffin followed by barium swallow should be obtained. Any substantial perforation requires surgical repair. Patients with perforations that are promptly recognized and treated surgically within 6 to $8 \mathrm{~h}$ have outcomes comparable with those of patients undergoing elective thoracotomy and Heller myotomy (39).

The surgical objective in the treatment of achalasia is to disrupt the LES enough to eliminate dysphagia without causing excessive reflux. Heller (40) first described the technique in 1913, proposing anterior and posterior gastroesophageal junction incisions after accessing the area by thoracotomy. Subsequent modifications include eliminating the posterior myotomy, shortening the anterior myotomy and accessing the area by laparotomy, thoracoscopy or, most recently, laparoscopy. Debate persists regarding the necessity and type of accompanying antireflux procedure. Illustrative of reflux complications is a surgical series in which recurrent dysphagia due to insufficient myotomy or periesophageal scarring occurred in $9 \%$ of patients three to 30 months postoperatively, while complications due to reflux ranging from esophagitis to Barrett's metaplasia occurred in $17 \%$ of patients 21 to 23 months postoperatively (41). There are also reports of adenocarcinoma developing as a late complication of postmyotomy reflux. However, just as surgical techniques have evolved, so has the medical therapy of reflux esophagitis, and these reflux complications would be unlikely if individuals had been treated with proton pump inhibitors. The trend is to use a laparoscopic approach for the myotomy, which requires some disruption of the phrenoesophageal ligament and mobilization of the esophagus (42). With this approach, at least a partial anterior fundoplication (Dohr procedure) is requisite.

Table 4 summarizes the efficacy of medical and surgical treatments of achalasia (38). Data in the table are uncontrolled because only one relevant controlled trial has been reported (see below). All data included were from consecutive series, although some were collected prospectively and others by retrospective review. These were combined in the table because the results were identical. The response rates reported in Table 4 are the proportion of patients with a 'good to excellent' response in each study. The response indicated for each therapy is a pooled estimate of response rate over multiple studies, with each study weighted proportionally to its sample size. Of note, the response rate indicates the number of individuals with a good to excellent response that was sustained until the end of the observation period without any further therapy. Thus, if a patient required a second dilation or a second injection, or if a laparoscopic operation was converted to an open procedure, these were considered failures of the initial treatment. The two efficacious therapies are pneumatic dilation and Heller myotomy (Table 4). Only one controlled trial has compared these therapies. That prospective, randomized trial compared pneumatic dilation (39 patients) with Heller myotomy via thoracotomy (42 patients), reporting 95\% nearly complete symptom resolution in the surgical group compared with $51 \%$ in the dilation group $(\mathrm{P}<0.01)$ after five years (range 24 to 156 months) (43). Included among the treatment failures in the dilation group were two patients who sustained perforations $(5.4 \%)$ and four $(10.8 \%)$ who subsequently had a good result with a second dilation. Although that report was criticized for the methodology of pneumatic dilation (44), it remains the best comparative data.

Choosing between using dilation or myotomy as the primary therapy for achalasia requires consideration of not only efficacy, but also available expertise and morbidity. In the case of pneumatic dilation, this is an outpatient procedure and, hence, it has less morbidity than any surgical approach with the caveat that the published incidence of esophageal perforation averages 3\%. Even though these patients do well if the perforation is recognized and operated on promptly, the perforation is invariably into the mediastinum, and there is no minimally invasive surgical option once that has occurred. Although the Heller myotomy is clearly efficacious, the greatest proportion of cases in Table 4 were accomplished by thoracotomy, which has considerable morbidity such that patients generally require several months to recover fully. More than any other factor, the morbidity of thoracotomy has historically led most patients to pneumatic dilation as the initial intervention. However, laparoscopic myotomy has efficacy similar to that of to an open myotomy, with substantially reduced morbidity. One recent series of 24 achalasia patients treated either thoracoscopically or laparoscopically had benefits similar to those of open procedures but a median hospitalization of only three days (compared with laparotomy and thoracotomy, which have an average hospitalization of seven to 10 days). Of course, these results are from a referral centre with substantial experience in both conventional and minimally invasive surgical therapy of achalasia.

In extremely advanced or refractory cases of achalasia, esophageal resection with gastric pull-up or interposition of 
TABLE 5

Clinical data on treatments for diffuse esophageal spasm, nutcracker esophagus and nonspecific esophageal motor disorders

\begin{tabular}{|c|c|c|c|c|}
\hline Treatment (reference) & $\begin{array}{l}\text { Number of } \\
\text { patients }\end{array}$ & Follow-up (years) & $\begin{array}{c}\text { Symptomatic } \\
\text { improvement (\%) }\end{array}$ & Comments \\
\hline \multicolumn{5}{|l|}{ Diffuse esophageal spasm } \\
\hline Nitrates (52) & 12 & 1.0 & 75 & $\begin{array}{l}\text { Prospective, less effective with } \\
\text { gastroesophageal reflux disease }\end{array}$ \\
\hline Botulinum toxin (56) & 5 & 0.8 & 60 & Prospective \\
\hline Pneumatic dilation (57) & 20 & 3.4 & 70 & Retrospective \\
\hline Pneumatic dilation (58) & 9 & 3.1 & 89 & Retrospective \\
\hline Pneumatic dilation (59) & 41 & 5.0 & 83 & Retrospective \\
\hline \multicolumn{5}{|l|}{ Nutcracker } \\
\hline Nifedipine (64) & 20 & 0.3 & 0 & Prospective, controlled, crossover \\
\hline Diltiazem (65) & 10 & 0.2 & 60 & Prospective, open label \\
\hline Antireflux therapy (66) & 12 & 0.2 & 83 & $\begin{array}{l}\text { Prospective, open label, high dose } \\
\text { ranitidine or omeprazole }\end{array}$ \\
\hline Bougienage (67) & 8 & 0.3 & 0 & Small diameter versus large diameter \\
\hline Long myotomy (68) & 4 & 2 & 100 & Retrospective \\
\hline \multicolumn{5}{|c|}{ Nonspecific esophageal motor disorders* } \\
\hline
\end{tabular}

All relevant studies are reported, regardless of study population size. Case reports are excluded. *Includes nutracker esophagus. N/A Not applicable

a segment of transverse colon may be the only surgical option (45). Patients with daily dysphagia and a tortuous esophagus with poor emptying despite multiple previous procedures are likely candidates. This technique is rarely, if ever, used as a primary intervention and, fortunately, is necessary in less than $1 \%$ of the achalasia population.

\section{DIFFUSE ESOPHAGEAL SPASM AND OTHER CONTRACTILE DISORDERS}

Unlike with achalasia, the esophagus of the patient with DES usually retains its ability to propagate primary peristaltic waves the majority of the time. Partly because of this fact, the criteria for diagnosing DES remain variable (46). There are no uniform radiographic, manometric or histopathological criteria for defining DES. In the unequivocal case, nonperistaltic, high amplitude, prolonged contractions are seen during esophageal manometry, and these are associated with chest pain or dysphagia. These unequivocal cases are rare and are probably associated with a defect in the neuronal architecture of deglutitive inhibition, placing them in the continuum of vigorous achalasia and achalasia (Table 2) (27). Ra- diographically, DES may appear as a 'corkscrew esophagus'. Similar to achalasia, the simultaneous contractions typifying diffuse esophageal spasm impair bolus transit through the esophagus, potentially explaining the associated dysphagia (47). It must be emphasized, however, that neither the tertiary contractions (nonperistaltic, simultaneous esophageal contractions) seen on $\mathrm{x}$-ray nor the simultaneous contractions seen manometrically are pathognomonic of esophageal spasm; both may be seen in asymptomatic individuals (4).

Diffuse esophageal spasm can potentially cause dysphagia and chest pain that may mimic that of angina pectoris. However, an esophageal etiology of chest pain should be considered only after careful consideration of potential cardiopulmonary etiologies. Furthermore, even within the spectrum of esophageal diseases, neither chest pain nor dysphagia is specific for a spastic disorder because both symptoms are also characteristic of common esophageal disorders including peptic, caustic or infectious esophagitis. After these more common diagnostic possibilities have been excluded by appropriate radiographic evaluation, endoscopic evaluation and in some instance a therapeutic trial of antisecretory 
medications, motility disorders may be considered. When chest pain patients are studied manometrically, achalasia and DES are relatively unusual findings (Table 2) (4). Achalasia is probably found in less than $1 \%$ of subjects when chest pain is the principal symptom. Likewise, DES is found in 5\% or fewer of chest-pain patients on average. The majority of manometric findings in this group of patients fall under the category of nonspecific disorders. The most common manometric patterns are of exaggerated contractions in the esophageal body (increased wave amplitudes, long duration, multipeaked waves) or of a hypertensive LES $(48,49)$. Of the group, increased wave amplitude (nutcracker esophagus) is the most commonly detected pattern. However, functional abnormalities associated with nonspecific motor disorders are not generally recognized, and long term observations have shown neither a parallel in clinical course with manometric findings nor consistency in manometric diagnosis over time $(4,50,51)$. Thus, it has been difficult to determine a direct relevance of nonspecific motility disturbances to either symptoms or function, making their detection of no generalizable value.

\section{MANAGEMENT}

Spastic disorders have been treated with the same pharmacological agents as achalasia (Table 5) (52-70). However, despite the dogma of treating esophageal spasm with smooth muscle relaxants, the single available placebo controlled, randomized crossover trial showed no efficacy for diltiazam (52). Long term outcome studies of the medical treatment of DES with smooth muscle relaxants are not available, and the entire basis of this therapy remains at an anecdotal level (71). With respect to the spastic disorders other than DES, the only large controlled trial showing efficacy was in the case of the antidepressant, trazadone (70) (Table 5). Therapeutic trials with smooth muscle relaxants, tranquilizers or bougiennage have shown no parallel between modification of manometric findings and therapeutic response $(65,68$, $70,72)$. Several controlled trials were able to show improvement of the manometric abnormality, but this did not correlate with symptomatic improvement. More impressive has been the finding that reflux disease is often responsible for symptoms of esophageal dysfunction whether nonspecific motor abnormalities are present or not. Bancewicz et al (73) found that intensive antireflux therapy was the most useful therapy for a large group of symptomatic patients without a specific motor disorder. Similarly, in a recent study, Achem et al (67) found that antireflux therapy benefited patients with unexplained chest pain, regardless of the presence or absence of nonspecific motor abnormalities. Furthermore, instances of esophageal pain attributable to reflux rather than spasm are likely made worse by treating with smooth muscle relaxants because of their effect on the LES.

There are no controlled studies of treatment of patients with DES with pneumatic dilation or myotomy (Table 4). Again emphasizing the rarity of well-defined cases of DES, the total number of patients in these reports treated by pneumatic dilation or myotomy was only 70 and 71 , respectively.

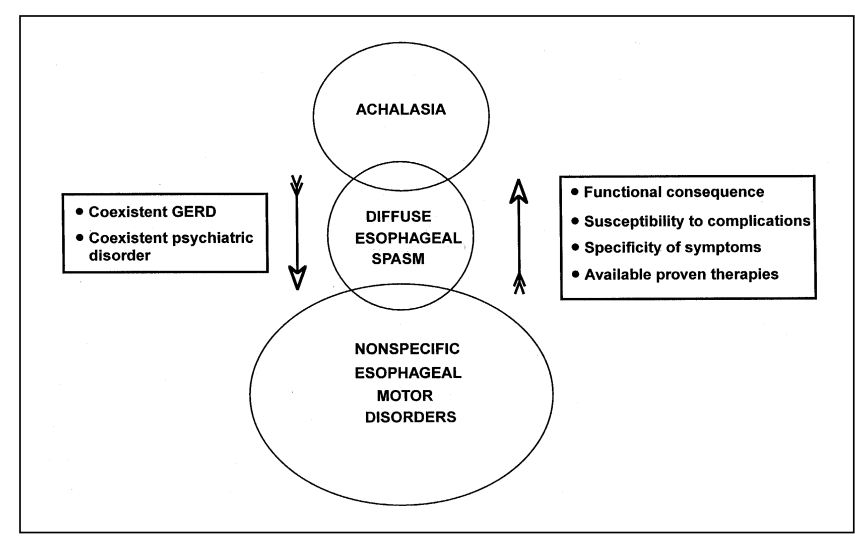

Figure 1) The universe of esophageal motility disorders. Some overlap exists between adjacent entities as suggested by the Venn diagram. The attributes indicated on the left are increasingly relevant going down the diagram, while those at the right are increasingly applicable moving up the diagram. GERD Gastroesophageal reflux disease

Nonetheless, the minimal treatment data that exist suggest that in these rare reported cases, pneumatic dilation or surgical myotomy are effective. One explanation for this might be that some cases of DES have been observed to evolve into achalasia, which clearly responds to these treatment strategies (74).

In summary, minimal data support the use of pharmacological agents in the long term management of DES, nutcracker esophagus or nonspecific esophageal motility disorders. In the case of DES, only anecdotal evidence exists. The most convincing treatment data pertain to pneumatic dilation or myotomy in patients with an extreme motor abnormality, suggesting that in these instances a major motor disorder exists, analogous to vigorous achalasia. However, it must be emphasized that the therapy of esophageal spasm is typically a trial and error experience reflecting the extreme inhomogeneity of the patient population. In the case of nutcracker esophagus and nonspecific esophageal motor disorders, it remains unclear as to whether or not the peristaltic aberrations cause the associated symptoms, and, to date, the most effective therapies have been directed at gastroesophageal reflux disease (GERD) or neurosis.

\section{CONCLUSIONS}

Within the universe of esophageal motility disorders, achalasia stands alone as a disease of well defined pathophysiology, obvious functional consequences and reasonably efficacious therapies (Table 4). Partially overlapping achalasia is DES, a disorder characterized by a severe (although often intermittent) peristaltic defect with functional and symptomatic consequences in some cases. Interestingly, DES most likely responds to specific therapy when it has features similar to vigorous achalasia, implying that it is part of a pathophysiological continuum in these cases. Alternatively, episodic esophageal spasm may be a manifestation of GERD, a disorder for which very effective therapies exist (75). However, the paucity of therapeutic data on DES emphasizes the rarity of this condition (Table 5). With respect to other 
esophageal motility disorders, the current therapy is as poorly defined as are the disorders themselves (Figure 1). Yet, these are the most prevalent manometric abnormalities detected in clinical practice (nutcracker esophagus, hypertensive LES and nonspecific disorders) characterized by peristaltic defects without clear functional or symptomatic consequences. Although in extreme instances these mimic DES in symptomatology and can exhibit profound esophageal hypercontractility, there is no evidence suggesting any relationship to achalasia. In fact, the clinical relevance of these disorders is controversial given that they are inconstant findings without an established link to symptomatology for which no specific therapy is efficacious. Although it is tempting to attribute diagnostic dilemmas to these coexistent subtle manometric abnormalities, supporting evidence has been elusive (Table 5). Thus, available data do not support any specific therapy aimed at the motility defects themselves. In view of the unproven value of detecting these manometric

\section{REFERENCES}

1. Osgood H. A peculiar form of esophagismus. Boston Med Surg J 1889

2. Lendrum FC. Anatomic features of the cardiac orifice of the stomach with special reference to cardiospasm. Arch Intern Med 1937;59:474-511.

3. Fleshler B. Diffuse esophageal spasm. Gastroenterology 1967:52:559-64.

4. Kahrilas PJ, Clouse RE, Hogan WJ. American Gastroenterological Association technical review on the clinical use of esophageal manometry. Gastroenterology 1994;107:1865-84.

5. Yamato S, Spechler SJ, Goyal RK. Role of nitric oxide in esophageal peristalsis in the opossum. Gastroenterology 1992;103:197-204.

6. Goyal RK, Rattan S. Genesis of basal sphincter pressure: effect of tetrodotoxin on lower esophageal sphincter pressure in opossum in vivo. Gastroenterology 1976;71:62-7.

7. Pouderoux P, Lin S, Kahrilas PJ. Timing, propagation, coordination, and effect of esophageal shortening during peristalsis. Gastroenterology 1997;112:1147-54.

8. Kahrilas PJ, Dodds WJ, Hogan WJ. The effect of peristaltic dysfunction on esophageal volume clearance. Gastroenterology $1988 ; 94: 73-80$.

9. Li M, Brasseur JG, Dodds WJ. Analyses of normal and abnormal esophageal transport using computer simulations. Am J Physiol 1994;266:G525-43.

10. Clouse RE, Staiano A. Topography of normal and high-amplitude esophageal peristalsis. Am J Physiol 1993;265:G1098-107.

11. Sifrim D, Janssens J, Vantrappen G. A wave of inhibition precedes primary peristaltic contraction in the human esophagus. Gastroenterology 1992;103:876-82.

12. Murray JA, Ledlow A, Launspach, J, Evans D, Loveday M, Conklin JL. The effects of recombinant human hemoglobin on esophageal motor function in humans. Gastroenterology 1995;109:1241-8.

13. Earlnam RJ, Ellis FH, Nobrega FT. Achalasia of the esophagus in a small urban community. Mayo Clin Proc 1969;44:478-83.

14. Howard PJ, Maher L, Pryde A, Cameron EWJ, Heading RC. Five year prospective study of the incidence, clinical features, and diagnosis of achalasia in Edinburgh. Gut 1992;33:1011-5.

15. Mayberry JF, Atkinson M. Studies of achalasia in the Nottingham area. Q J Med 1985;56:451-6.

16. Cook IJ, Kahrilas PJ. AGA technical review on the management of oropharyngeal dysphagia. Gastroenterology 1999;116:455-78.

17. Dantas RO, Cook IJ, Dodds WJ, et al. Biomechanics of cricopharyngeal bars. Gastroenterology 1990;99:1269-74.

18. Cook IJ, Gabb M, Panagopoulos V, et al. Pharyngeal (Zenker's) diverticulum is a disorder of upper esophageal sphincter opening. Gastroenterology 1992;103:1229-35.

19. Cook IJ, Blumberos P, Cash K, Jamieson GG, Shearman DJ. aberrations, practice guidelines currently do not support pursuing them in the evaluation of chest pain patients (76). Rather, until the meaning of these aberrations of esophageal motility are better understood, we should not overlook therapy aimed at the most common esophageal disorder (GERD) or more global conditions such as depression or somatization neurosis that are often coexistent in these patients. Consistent with these guidelines, clinical practice patterns have shifted over the past decade, refocusing the utilization manometric evaluations on dysphagia and as a preoperative evaluation for antireflux surgery, as opposed to the evaluation of chest pain $(77,78)$.

ACKNOWLEDGEMENT: Supported by grant RO1 DC00646 from the Public Health Service. The author expresses appreciation to Anita E Spiess for her tireless pursuit of the literature on the treatment of esophageal motility disorders, the resultant distillation of which is a cornerstone of this manuscript.
Structural abnormalities of the cricopharyngeus muscle in patients with pharyngeal (Zenker's) diverticulum. J Gastroenterol Hepatol 1992;7:556-62.

20. Ali GN, Wallace KL, Schwartz R, de Carle DJ, Zagami A, Cook IJ. Mechanisms of oral-pharyngeal dysphagia in patients with Parkinson's disease. Gastroenterology 1996;110:383-92.

21. Johnston BT, Castell JA, Stumacher S, et al. Comparison of swallowing function in Parkinson's disease and progressive supranuclear palsy. Mov Disord 1997;12:322-7.

22. Bushmann M, Dobmeyer SM, Leeker L, Perlmutter JS. Swallowing abnormalities and their response to treatment in Parkinson's disease. Neurology 1989;39:1309-14.

23. Kahrilas PJ, Dodds WJ, Dent J, Wyman JB, Hogan WJ, Arndorfer RC. Upper esophageal sphincter function during belching. Gastroenterology 1986;91:133-40.

24. Shaker R, Ren J, Kern M, Dodds WJ, Hogan WJ, Li Q. Mechanisms of airway protection and upper esophageal sphincter opening during belching. Am J Physiol 1992;262:G621-8.

25. Kahrilas PJ, Dodds WJ, Hogan WJ. Dysfunction of the belch reflex: a cause of incapacitating chest pain. Gastroenterology 1987;93:818-22.

26. Hurwitz AL, Duranceau A, Haddad JK. Oropharyngeal dysphagia. In: Smith LE, ed. Major Problems in Internal Medicine, Volume XVI: Disorders of Esophageal Motility. Philadelphia: WB Saunders Co, 1979:67-84.

27. Sifrim D, Janssens J, Vantrappen G. Failing deglutitive inhibition in primary esophageal motility disorders. Gastroenterology 1994;106:875-82.

28. Hirsch DP, Hollowy RH, Tytgat GNJ, Boeckxstaens GEE. Involvement of nitric oxide in human transient lower esophageal sphincter relaxations and esophageal primary peristalsis. Gastroenterology 1998;115:1374-80.

29. Shi G, Ergun GA, Manka M, Kahrilas PJ. LES relaxation characteristics using a sleeve sensor in clinical manometry. Am J Gastroenterol 1998;93:2373-9.

30. Kahrilas PJ, Kishk SM, Helm JF, Dodds WJ, Harig JM, Hogan WJ. A comparison of pseudoachalasia and achalasia. Am J Med 1987;82:439-46.

31. Song CW, Chun HJ, Kim CD, Ryu HS, Hyun JH, Kahrilas PJ. The association of pseudoachalasia with advancing cancers of gastric cardia. Gastrointest Endosc 1999;50:486-91.

32. Sandler RS, Nyren O, Ekbom NO, Eisen GM, Yuen J, Josefsson S. The risk of esophageal cancer in patients with achalasia. A population-based study. JAMA 1995;274:1359-62.

33. Eckardt VF, Aignherr C, Bernhard G. Predictors of outcome in patients with achalasia treated by pneumatic dilation. Gastroenterology 1992;103:1732-8.

34. Gelfond M, Rozen P, Gilat T. Isosorbide dinitrate and nifedipine 
treatment of achalasia: a clinical, manometric and radionuclide evaluation. Gastroenterology 1982;83:963-9.

35. Traube M, Albibi R, McCallum RW. High-amplitude peristaltic esophageal contractions associated with chest pain. JAMA 1983;250:2655-9.

36. Pasricha PJ, Ravich WJ, Hendrix TR, Sostre S, Jones B, Kalloo AN. Intrasphincteric botulinum toxin for the treatment of achalasia. N Engl J Med 1995;322:774-8.

37. Pasricha P, Rai R, Ravich W, Hendrix T, Kalloo A. Botulinum toxin for achalasia: Long-term outcome and predictors of response. Gastroenterology 1996;110:1410-5.

38. Spiess AE, Kahrilas PJ. Treating achalasia: from whalebone to laparoscope. JAMA 1998;280:638-42.

39. Schwartz HM, Cahow CE, Traube M. Outcome after perforation sustained during pneumatic dilation for achalasia. Dig Dis Sci 1993;38:1409-13.

40. Heller E. Heller E. Extramukose Cardioplastic beim chronishen Cardiospasmus mit Dilatation des Oesophagus. Mitt Grenzeg Med Chir 1913;27:141.

41. Mattioli S, Di Simone MP, Bassi F, et al. Surgery for esophageal achalasia. Long-term results with three different techniques. Hepatogastroenterology 1996;43:492-500.

42. Hunter JG, Trus TL, Branum GD, Waring JP. Laparoscopic Heller myotomy and fundoplication for achalasia. Ann Surg 1997;6:655-65.

43. Csendes A, Braghetto I, Henriquez A, Cortes C. Late results of a prospective randomised study comparing forceful dilatation and oesophagomyotomy in patients with achalasia. Gut 1989;30:299-304.

44. Richter JE. Surgery or pneumatic dilatation for achalasia: a head-to-head comparison. Now are all the questions answered? Gastroenterology 1989;97:1340-1.

45. Ellis Jr FH. Oesophagomyotomy for achalasia: a 22-year experience. Br J Surg 1993;80:882-5.

46. Richter JE, Castell DO. Diffuse esophageal spasm: a reappraisal. Ann Intern Med 1984;100:242-5.

47. Massey BT, Dodds WJ, Hogan WJ, Brasseur JG, Helm JF. Abnormal esophageal motility. An analysis of concurrent radiographic and manometric findings. Gastroenterology 1991;101:344-54.

48. Benjamin SB, Gerhardt DC, Castell DO. High amplitude, peristaltic esophageal contractions associated with chest pain and/or dysphagia. Gastroenterology 1979;77:478-83.

49. Traube M, Hongo M, Magyar L, McCallum RW. Effects of nifedipine in achalasia and in patients with high-amplitude peristaltic esophageal contractions. JAMA 1984;252:1733-6.

50. Achem SR, Crittenden J, Kolts B, Burton L. Long-term clinical and manometric follow-up of patients with nonspecific esophageal motor disorders. Am J Gastroenterol 1992;87:825-30.

51. Swift GL, Alban-Davies H, McKirdy H, Lowndes R, Lewis D, Rhodes J. A long-term clinical review of patients with oesophageal chest pain. Q J Med 1991;81:937-44.

52. Drenth JPH, Bos LP, Engels LGJ. Efficacy of diltiazem in the treatment of diffuse oesophageal spasm. Aliment Pharmacol Ther 1990;4:411-6.

53. Swamy N. Esophageal spasm: Clinical and manometric response to nitroglycerine and long acting nitrites. Gastroenterology 1977;72:23-7.

54. Mellow M. Symptomatic diffuse esophageal spasm. Manometric follow-up and response to cholinergic stimulation and cholinesterase inhibition. Gastroenterology 1977;73:237-40.

55. Thomas E, Witt P, Willis M, Morse J. Nifedipine therapy for diffuse esophageal spasm. South Med J 1986;79:847-9.

56. Irving D, Owen WJ, Linsell J, McCullagh M, Keightley A, Anggiansah A. Management of diffuse esophageal spasm with balloon dilatation. Gastrointest Radiol 1992;17:189-92.
57. Miller LS, Parkman HP, Schiano TD, et al. Treatment of symptomatic nonachalasia esophageal motor disorders with botulinum toxin injection at the lower esophageal sphincter. Dig Dis Sci 1996;41:2025-31.

58. Irving D, Owen WJ, Linsell J, McCullagh M, Keightley A, Anggiansah A. Management of diffuse esophageal spasm with balloon dilatation. Gastrointest Radiol 1992;17:189-92.

59. Ebert EC, Ouyang A, Wright SH, Cohen S, Lipshutz WH. Pneumatic dilatation in patients with symptomatic diffuse esophageal spasm and lower esophageal sphincter dysfunction. Dig Dis Sci 1983;28:481.

60. Bourgeois N, Coffernils M, Buset M, et al. Management of dysphagia in suspected esophageal motor disorders. Dig Dis Sci 1991;36:268-73.

61. Eypasch E, DeMeester T, Klingman R, Stein H. Physiologic assessment and surgical management of diffuse esophageal spasm. J Thorac Cardiovasc Surg 1992;104:859-69.

62. Ellis FH Jr. Esophagomyotomy for noncardiac chest pain resulting from diffuse esophageal spasm and related disorders. Am J Med 1992;92:129S-31S.

63. Filipi CJ, Hinder RA. Thoracoscopic esophageal myotomy - a surgical technique for achalasia diffuse esophageal spasm and "nutcracker esophagus". Surg Endosc 1994;8:921-6.

64. Patti MG, Pellegrini CA, Arcerito M, Tong J, Mulvihill SJ, Way LW. Comparison of medical and minimally invasive surgical therapy for primary esophageal motility disorders. Arch Surg 1995;130:609-16.

65. Richter JE, Dalton CB, Bradley LA, Castell DO. Oral nifedipine in the treatment of noncardiac chest pain in patients with nutcracker esophagus. Gastroenterology 1987;93:21-8.

66. Richter JE, Spurling TJ, Cordova CM, et al. Effects of oral calcium blocker, diltiazem, on esophageal contractions. Dig Dis Sci 1984;29:649-56

67. Achem SR, Kolts BE, Wears R, Burton L, Richter JE. Chest pain associated with nutcracker esophagus: a preliminary study of the role of gastroesophageal reflux. Am J Gastroenterol 1993;88:187-92.

68. Winters C, Artnak EJ, Benjamin SB, Castell DO. Esophageal bougenage in symptomatic patients with the nutcracker esophagus. JAMA 1984;252:363-6.

69. Traube M, Tummala, V, Baue AE, McCallum RW. Surgical myotomy in patients with high-amplitude peristaltic esophageal contractions. Dig Dis Sci 1987;32:16-21.

70. Clouse RE, Lustman PJ, Eckert TC, Ferney DM, Griffith LS. Low-dose trazodone for symptomatic patients with esophageal contraction abnormalities. Gastroenterology 1987;92:1027-36.

71. McCord GS, Staiano A, Clouse RE. Achalasia, diffuse esophageal spasm and non-specific motor disorders. Baillieres Clin Gastroenterol 1991;5:307-35.

72. Cattau EL, Castell DO, Johnson DA, et al. Diltiazam therapy for symptoms associated with nutcracker esophagus. Am J Gastroenterol 1991;86:272-5.

73. Bancewicz J, Osugi H, Marples M. Clinical implications of abnormal oesophageal motility. Br J Surg 1987;74:416-9.

74. Vantrappen G, Janssens J, Henemans J, Coremans G. Achalasia, diffuse esophageal spasm and related motiity disorders. Gastroenterology 1979;76:450-7.

75. Kahrilas PJ. Gastroesophageal reflux disease. JAMA 1996;276:983-8.

76. American Gastroenterological Association. An American Gastroenterological Association medical position statement on the clinical use of esophageal manometry. Gastroenterology 1994;107:1865.

77. Kahrilas PJ. Nutcracker esophagus: an idea whose time has gone? Am J Gastroenterol 1993;88:167-9.

78. Alrakawi A, Clouse RE. The changing use of esophageal manometry in clinical practice. Am J Gastroenterol 1998;93:2359-62. 


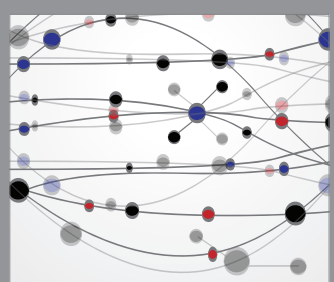

The Scientific World Journal
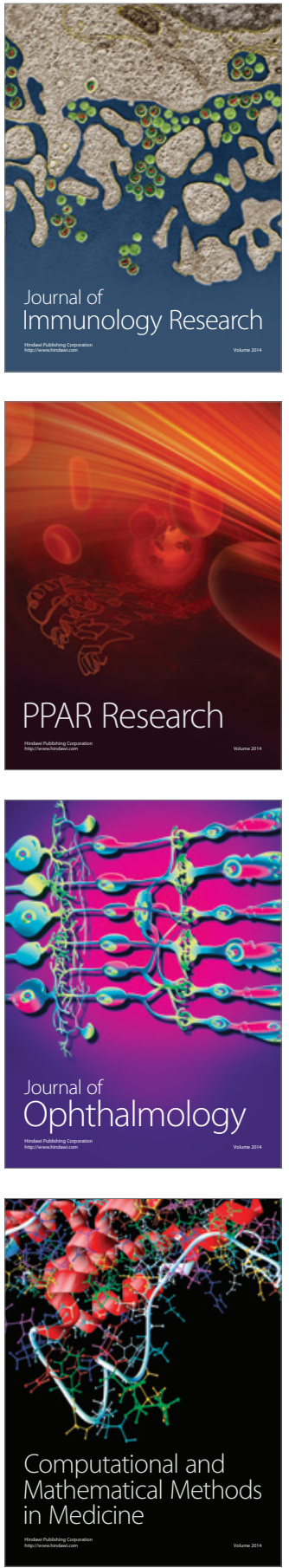

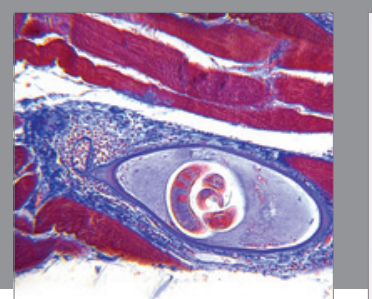

Gastroenterology Research and Practice

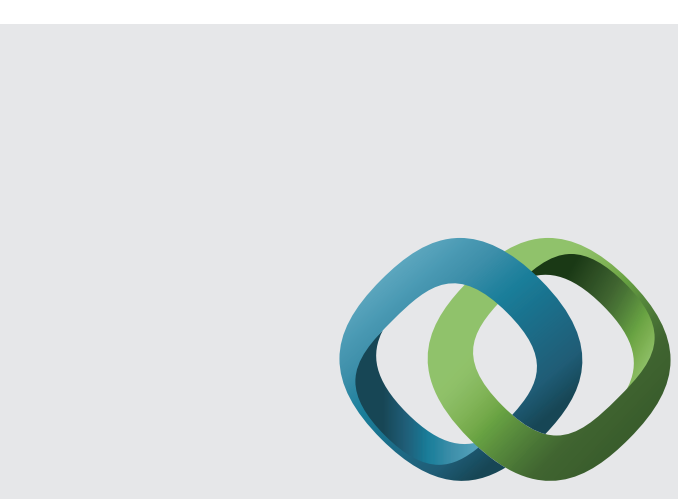

\section{Hindawi}

Submit your manuscripts at

http://www.hindawi.com
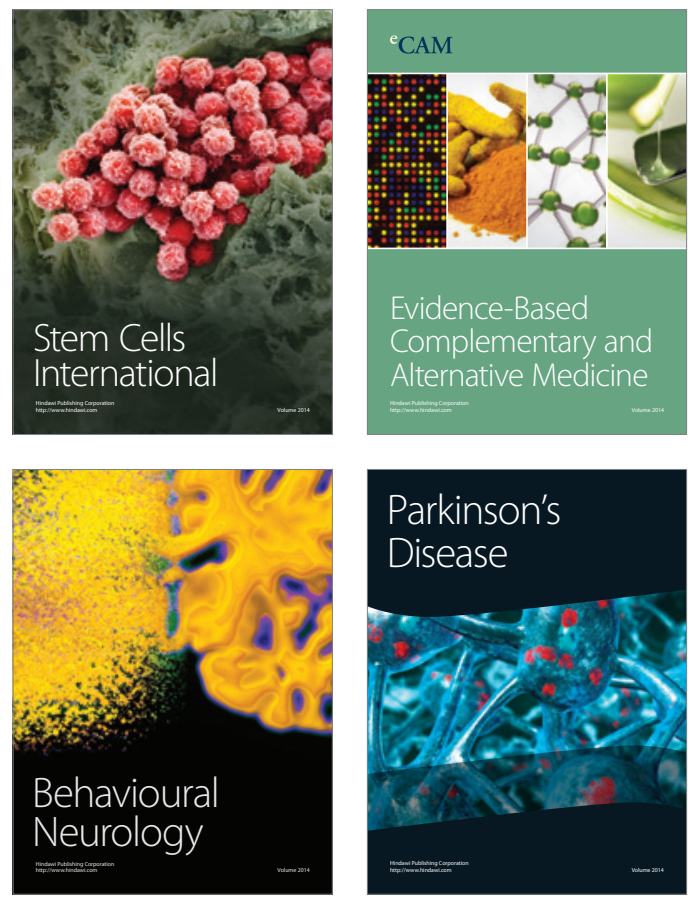
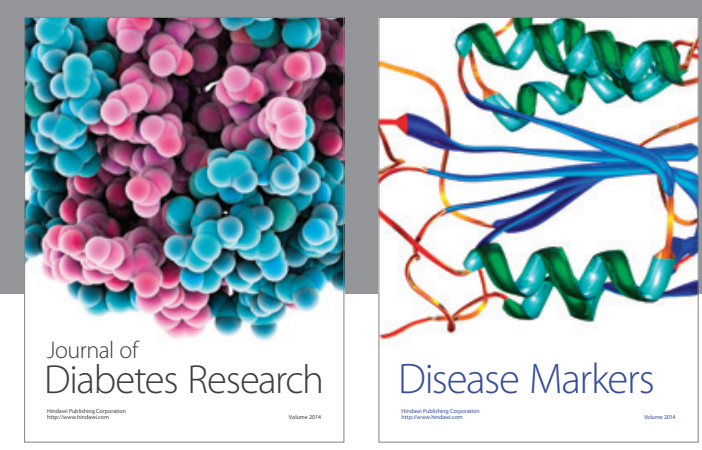

Disease Markers
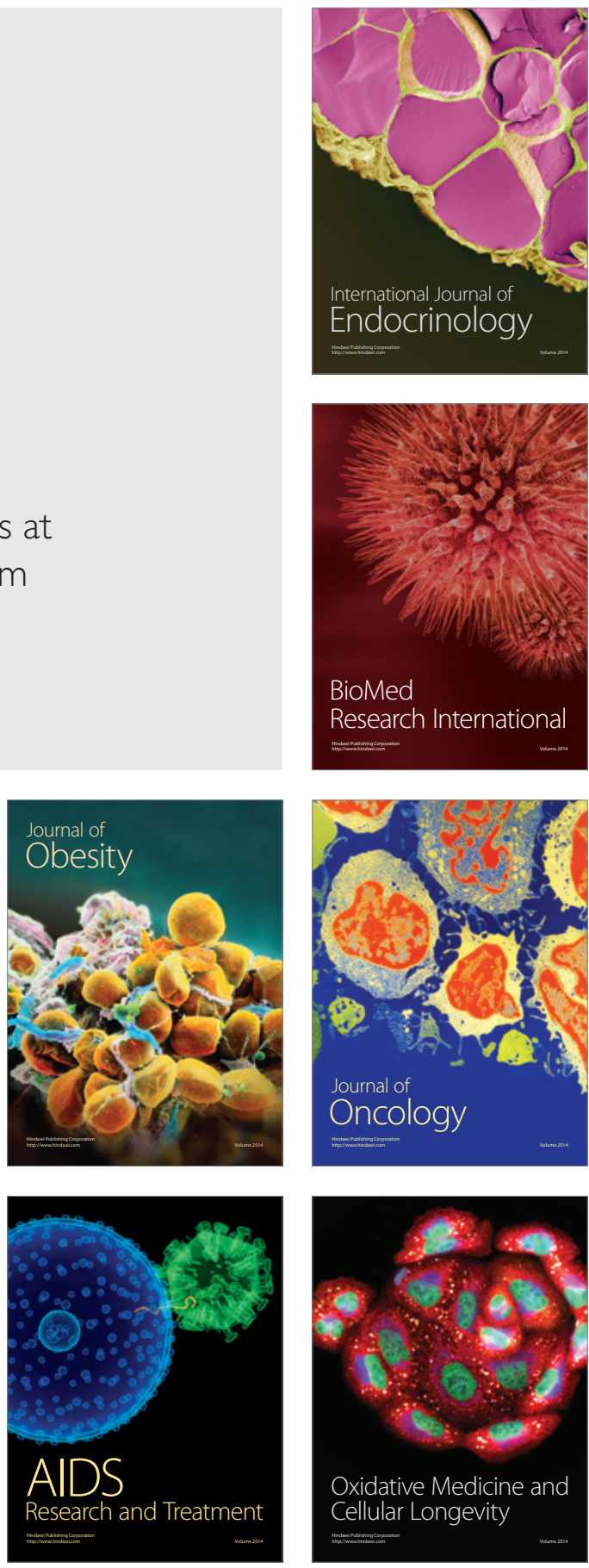